\title{
Biologi dan Kemampuan Memangsa Paederus fuscipes Curtis (Coleoptera: Staphylinidae) terhadap Bemisia tabaci Gennadius (Homoptera: Aleyrodidae)
}

\author{
Sudarjat ${ }^{1}$, Argo Utomo ${ }^{2}$ dan Danar Dono ${ }^{1}$ \\ 'Jurusan Hama dan Penyakit Tumbuhan Fakultas Pertanian Universitas Padjadjaran \\ ${ }^{2}$ Alumni Jurusan Hama dan Penyakit Tumbuhan Fakultas Pertanian Universitas Padjadjaran \\ Jalan Raya Jatinangor KM-21, Bandung 40600 \\ Korespondensi: ajat_proteksi@yahoo.com
}

\begin{abstract}
Biology and preying ability of Paederus fuscipes Curtis (Staphylinidae) on Bemisia tabaci Gennadius (Homoptera: Aleyrodidae)

Bemisia tabaci is one of the major in vegetable production and causes economic lost up to $100 \%$. It was reported that Paederus fuscipes is able to prey B. tabaci in vegetables field in Ciwidey, Bandung. The greenhouse studies were conducted to observe the biology of P. fuscipes and its adult male feeding ability on B. tabaci. The experiment was arranged in Completely Randomized Block Design with five treatments and five replications. The treatments were infesting 10, 20, 40,80, and 160 nymphs of $B$. tabaci per one adult $P$. fuscipes. The result showed that the life cycle of $P$. fuscipes was 38-75 days. The egg stage was 4-7 days, the $1^{\text {st }}$ instar larvae stage was $4-5$ days, the $2^{\text {nd }}$ instar larvae stage was 6-9 days, the pre-pupae stage was 2-3 days, the pupae stage was 3-5 days and the adult stage was 19-46 days. P. fuscipes responsed functionally to the increase of $B$. tabaci nymph density. One adult of $P$. fuscipes was able to feed up to 101.1 nymph in the afternoon period and 100.1 in the morning period, or $0.83-8.17$ nymphs per hour on the day and $0.75-8$ nymphs per hour in the night.
\end{abstract}

Key words: Bemisia tabaci, Paederus fuscipes, Preying ability.

\begin{abstract}
ABSTRAK
Bemisia tabaci merupakan hama tanaman di beberapa sentra produksi sayuran hingga mengakibatkan kerugian ekonomi sampai $100 \%$. Paederus fuscipes merupakan predator B. tabaci pada beberapa tanaman di Kecamatan Ciwidey, Bandung. Penelitian bertujuan untuk mengetahui biologi dan kemampuan memangsa imago $P$. fuscipes jantan terhadap nimfa $B$. tabaci. Percobaan menggunakan Rancangan Acak Kelompok yang terdiri atas lima perlakuan dan 5 ulangan. Perlakuan terdiri atas: infestasi 10, 20, 40, 80, dan 160 nimfa B. tabaci per satu imago P. Fuscipes. Hasil pengamatan biologi menunjukkan bahwa siklus hidup $P$. fuscipes berkisar antara 38-75 hari. Fase telur berkisar 4-7 hari, larva instar-1 berkisar 4-5 hari, larva instar-2 berkisar 6-9 hari, pra-pupa berkisar 2-3 hari, pupa berkisar 3-5 hari, dan lama hidup imago berkisar 19-46 hari. P. fuscipes memperlihatkan tanggap fungsional terhadap peningkatan kepadatan $B$. tabaci sebagai mangsa. Jumlah pemangsaan nimfa $B$. tabaci tertinggi terjadi pada kepadatan 160 nimfa, yaitu 101,1 dan 100,1 nimfa $B$. tabaci per imago $P$. fuscipes, masing-masing untuk periode pagi dan sore. Kecepatan memangsa imago $P$. fuscipes terhadap nimfa $B$. tabaci yaitu berkisar 0,83-8,17 nimfa per jam pada siang hari, dan $0,75-8$ nimfa per jam pada malam hari.
\end{abstract}

Kata kunci: Bemisia tabaci, Paederus fuscipes, Kemampuan memangsa. 


\section{PENDAHULUAN}

Pestisida antara lain digunakan petani untuk mengendalikan hama tanaman. Penggunaan pestisida oleh petani semakin berlebihan karena pemilihan jenis dan cara aplikasi yang kurang efektif dan efisien sehingga manfaat yang diperoleh petani semakin menurun (Untung, 1996).

Hama tanaman yang sekarang mendapat perhatian serius adalah hama kutu kebul Bemisia tabaci Gennadius (Homoptera: Aleyrodidae) yang menyerang beberapa macam komoditas tanaman. B. tabaci pertama kali ditemukan di Indonesia pada tanaman tembakau pada tahun 1938 (Setiawati et. al., 2005). Selain di Indonesia, B. tabaci sudah menyerang berbagai macam tanaman di berbagai negara seperti India, Sudan, Iran, El Salvador, Mexico, Brazil, Turki, Israel, Thailand, Jepang dan Amerika Serikat (Hirano et al., 2006).

Serangan hama antara lain disebabkan terganggunya keseimbangan populasi organisme pada jenjang populasi tertentu. Penyebabnya adalah faktor lingkungan dan juga faktor di dalam populasi sendiri, yang mengendalikan perkembangan populasi tersebut (Sosromarsono \& Untung, 2006). Salah satu faktor lingkungan yang mengendalikan populasi hama adalah musuh alami baik berupa predator, parasitoid maupun patogen. Musuh alami dikenal sebagai faktor pengatur dan pengendali populasi serangga hama yang efektif karena sifat pengaturannya yang tergantung kepadatan populasi (Untung, 1996).

Ciri-ciri predator yang unggul adalah mampu memangsa dan tanggap terhadap peningkatan populasi mangsa (Taulu, 2001). Paederus fuscipes Curtis (Coleoptera: Staphylinidae) merupakan salah satu predator yang ditemukan pada beberapa tanaman yang terserang $B$. tabaci di daerah Kecamatan Ciwidey, Kabupaten Bandung, dan populasinya cukup melimpah (Sudarjat, 2008).

Pengamatan tingkah laku dan biologi predator adalah kunci yang penting untuk memahami cara hidup predator, dan selanjutnya pengaruh predator terhadap dinamika populasi inang atau mangsanya. Pengamatan ini juga berguna untuk menentukan jenis predator yang memiliki potensi tertinggi dalam mengendalikan serangga hama dan untuk mengevaluasi kemampuan predator setelah dilepaskan di lapangan (Feraru \& Mustata, 2004). Dengan dilaksanakannya penelitian ini diharapkan dapat diketahui tingkah laku dan lama hidup $P$. fuscipes, waktu dan jumlah $P$. fuscipes yang dihasilkan pada generasi kedua, perbandingan jantan dan betina keturunan, serta kemampuan memangsa dan tanggapannya terhadap peningkatan populasi hama.

\section{BAHAN DAN METODE}

\section{Uji Biologi $P$. fuscipes}

Sepuluh pasang $P$. fuscipes dewasa masing-masing dimasukkan ke dalam 10 stoples (diameter $14 \mathrm{~cm}$ dan tinggi $7 \mathrm{~cm}$ ) yang berbeda yang telah diisi tanah halus setebal $1 \mathrm{~cm}$ dan ditutup oleh sedikit serasah serta ditempatkan di rumah kaca. Suhu rumah kaca pada saat percobaan berkisar antara $21^{\circ} \mathrm{C}-27{ }^{\circ} \mathrm{C}$ dan kelembaban rata-rata berkisar antara $63 \%-$ $79 \%$. Setelah terjadi kopulasi, mulai hari ke dua, diamati masa oviposisi dan jumlah telur yang dihasilkan betina serta keperidiannya. Pengamatan telur ini termasuk juga lama inkubasi telur, jumlah telur yang menetas dan persentasenya.

Larva dari telur yang telah menetas kemudian dipelihara dengan memberi nimfa B. tabaci sebagai makanan. Selama 70 hari diamati perkembangan fase pertumbuhannya yang meliputi larva, pupa dan imago. Pengamatan sex ratio dilakukan terhadap seluruh telur yang dihasilkan yang diambil dari setiap stoples. Dengan demikian semuanya terdapat 10 kelompok telur yang kemudian dipindahkan ke dalam stoples yang berbeda untuk diamati perkembangannya hingga dewasa, agar bisa diamati jenis kelaminnya dan perbandingan antara jantan dan betina. Siklus hidup $P$. fuscipes diamati dengan menghitung lama waktu dari telur menjadi larva, pupa, imago, kemudian saat imago menghasilkan keturunan pertama.

\section{Uji Predasi $P$. fuscipes}

Rancangan percobaan uji predasi $P$. fuscipes terhadap B. tabaci adalah Rancangan Acak Kelompok dengan lima perlakuan dan masing-masing diulang lima kali. Perlakuan berupa variasi jumlah nimfa $B$. tabaci yang diberikan kepada satu imago $P$. fuscipes, yaitu 10, 20, 40, 80 dan 160 nimfa $P$. fuscipes.

Nimfa B. tabaci instar empat yang terdapat pada daun labu dengan jumlah sesuai perlakuan ditempatkan di dalam stoples (diameter $14 \mathrm{~cm}$ dan tinggi $7 \mathrm{~cm}$ ). Setiap perlakuan diinfestasi satu ekor imago $P$. fuscipes jantan yang sebelumnya tidak diberi makan selama 24 jam. Stoples ditempatkan di rumah kaca selama tujuh hari.

Tingkat pemangsaan ditentukan dengan mengamati jumlah mangsa yang hilang atau rusak karena dimangsa. Pengamatan dibagi menjadi dua 
periode, yaitu pengamatan pagi pada pukul 06.00 sampai pukul 18.00 dan pengamatan sore pada pukul 18.00 sampai pukul 06.00. Penggantian nimfa $B$. tabaci dilakukan setiap 12 jam dengan jumlah sesuai perlakuan. Data yang diperoleh dianalisis secara statistik dengan Analisis Ragam menggunakan SPSS for Macintosh V. 11.0.4. Untuk mengetahui perbedaan di antara perlakuan dilakukan Uji Jarak Berganda Duncan pada taraf $5 \%$.

\section{HASIL DAN PEMBAHASAN}

\section{Karakteristik Biologi $P$. fuscipes}

Siklus Hidup

Siklus hidup $P$. fuscipes berkisar antara 38-75 hari, lama hidup imago 19-46 hari, stadia telur adalah 4-7 hari, larva instar-1 selama 4-5 hari, larva instar-2 selama selama 6-9 hari, pra-pupa selama 2-3 hari, dan pupa 3-5 hari (Tabel 1).

Tabel 1. Siklus Hidup P. fuscipes

\begin{tabular}{lcc}
\hline \multicolumn{1}{c}{ Tahap Perkembangan } & $\begin{array}{c}\text { Ukuran } \\
(\mathrm{mm})\end{array}$ & $\begin{array}{c}\text { Lama Stadia } \\
\text { (hari) }\end{array}$ \\
\hline Telur & $0,5-0,7$ & $4-7$ \\
Larva instar-1 & 1,6 & $4-5$ \\
Larva instar-2 & $2,3-3,3$ & $6-9$ \\
Larva instar-3 (pra-pupa) & $4,0-5,0$ & $2-3$ \\
Pupa & $5,0-5,5$ & $3-5$ \\
Imago & $7,0-8,0$ & $19-46$ \\
\hline
\end{tabular}

Siklus hidup $P$. fuscipes di Jatinangor relatif lebih lama dibandingkan dengan hasil percobaan di Bogor yang dilakukan oleh Laba \& Killin (1991) untuk mangsa wereng batang coklat (WBC) dengan lama stadia telur 4 hari, larva 9,2 hari, pra-pupa 1 hari dan pupa 3,8 hari. Perbedaan ini diduga karena perbedaan ketinggian tempat, suhu rata-rata harian serta kelembaban di Jatinangor. Suhu harian rata-rata di Bogor lebih tinggi sehingga perkembangan dan siklus hidup serangga lebih cepat dibandingkan dengan di Jatinangor. Hasil percobaan di Malang didapatkan rata-rata umur stadium telur 6,11 hari; larva instar II 11,68 hari; prepupa 1,96 hari; pupa 4,14 hari; serta imago 24,6 hari (Rahardjo, 1997).

\section{Telur, Keperidian dan Sex Ratio}

Jumlah telur yang dihasilkan imago betina $P$. fuscipes, berkisar antara 18-28 butir. Menurut Clausen (1972), jumlah telur yang dihasilkan oleh seekor betina berkisar antara 20-30 butir. Rata-rata peletakan telur tiap betina adalah 23,7 butir telur dan rata-rata telur yang menetas adalah 19,8 butir telur, dengan persentase penetasan telur $84 \%$ (Tabel 2).

Tabel 2. Keperidian dan persentase penetasan telur $P$. fuscipes

\begin{tabular}{cccc}
\hline No Sampel Jumlah Telur & $\begin{array}{c}\text { Jumlah telur } \\
\text { menetas }\end{array}$ & $\begin{array}{c}\text { Persentase } \\
\text { penetasan }\end{array}$ \\
\hline 1 & 24 & 19 & 79 \\
2 & 27 & 24 & 89 \\
3 & 23 & 17 & 74 \\
4 & 22 & 18 & 82 \\
5 & 21 & 19 & 90 \\
6 & 18 & 15 & 83 \\
7 & 19 & 17 & 89 \\
8 & 28 & 24 & 86 \\
9 & 27 & 20 & 74 \\
10 & 28 & 25 & 89 \\
\hline Rata-rata & 23.7 & 19.8 & 84 \\
\hline
\end{tabular}

Telur yang tidak menetas mencapai 16\%, diduga karena kurang sesuainya tanah yang digunakan untuk tempat bertelurnya $P$. fuscipes. Pada percobaan ini tanah yang digunakan berliat, sehingga penambahan air untuk menjaga kelembaban tanah menyebabkan tanah menjadi lengket. Clausen (1972) dan Petersen (1997) berpendapat bahwa pada tanah berliat telur $P$. fuscipes lebih banyak yang mati dan tidak menetas dibandingkan dengan pada tipe tanah berpasir.

Telur diletakkan secara terpisah pada permukaan tanah dan di bawah serasah daun. Telur berbentuk bulat, pada awalnya berwarna kuning jernih, sedangkan telur yang siap menetas berwarna kuning pekat atau coklat. Karakteristik ini sesuai dengan hasil pengamatan Rahardjo et al. (1997), bahwa $P$. fuscipes meletakkan telurnya secara tunggal, telur berbentuk hampir bulat, telur menetas pada lingkungan yang lembab dan pada suhu yang sesuai $\left(18^{\circ} \mathrm{C}-30^{\circ} \mathrm{C}\right)$, sedangkan pada saat penelitian ini dilaksanakan suhu berkisar $21^{\circ} \mathrm{C}-27^{\circ} \mathrm{C}$.

Sex ratio keturunan jantan dan betina yang diperoleh dari hasil pengamatan yaitu 0,89:1 (Tabel 3). P. fuscipes merupakan serangga yang berkembangbiak melalui perkawinan (Devi et al., 2004). Sex ratio $P$. fuscipes cenderung lebih banyak betina dibandingkan dengan jantan. Rasio ini sangat baik mengingat salah satu sifat predator yang baik 
adalah jumlah betina lebih banyak daripada jantan sehingga populasi lebih cepat berkembang. Menurut Jha (2002) sex ratio jantan dan betina $P$. fuscipes pada penetasan telur di laboratorium adalah 0,9 .

Tabel 3. Sex Ratio keturunan P. fuscipes

\begin{tabular}{|c|c|c|c|c|}
\hline \multirow{2}{*}{$\begin{array}{c}\text { Jumlah } \\
\text { telur } \\
\text { menetas }\end{array}$} & \multirow{2}{*}{$\begin{array}{c}\text { Jumlah } \\
\text { jantan } \\
\text { (ekor) }\end{array}$} & \multirow{2}{*}{$\begin{array}{c}\text { Jumlah } \\
\text { betina } \\
\text { (ekor) }\end{array}$} & \multicolumn{2}{|c|}{ Persentase } \\
\hline & & & Jantan & Betina \\
\hline 19 & 9 & 10 & 47 & 53 \\
\hline 24 & 10 & 14 & 42 & 58 \\
\hline 17 & 9 & 8 & 53 & 47 \\
\hline 18 & 9 & 9 & 50 & 50 \\
\hline 19 & 8 & 11 & 42 & 58 \\
\hline 15 & 7 & 8 & 47 & 53 \\
\hline 17 & 9 & 8 & 53 & 47 \\
\hline 24 & 11 & 13 & 46 & 54 \\
\hline 20 & 9 & 11 & 45 & 55 \\
\hline 25 & 12 & 13 & 48 & 52 \\
\hline 198 & 93 & 105 & 47 & 53 \\
\hline Sex Ratio & 0,89 & 1 & & \\
\hline
\end{tabular}

\section{Tingkat Predasi dan Kecepatan Memangsa} $P$. fuscipes terhadap $B$. tabaci

Tingkat pemangsaan imago $P$. fuscipes jantan pada siang dan malam hari tidak berbeda yang ditunjukkan oleh jumlah nimfa $B$. tabaci yang dimangsa pada siang hampir sama dengan pada malam hari (Tabel 4). Dengan demikian aktivitas $P$. fuscipes dalam mencari mangsa $B$. tabaci adalah sama baiknya pada siang hari maupun pada malam hari. Rata-rata banyaknya mangsa yang dikonsumsi meningkat dengan bertambahnya kepadatan mangsa. Hal ini menunjukkan bahwa $P$. fuscipes memperlihatkan tanggap fungsional terhadap nimfa B. tabaci.
Taulu (2001) mengemukakan bahwa selain perilaku pemilihan mangsa, predator umumnya memberikan tanggap fungsional terhadap peningkatan populasi mangsa. Dalam hal ini, jumlah mangsa yang dikonsumsi oleh satu individu predator bertambah dengan meningkatnya populasi mangsa. Tingkat pemangsaan oleh predator dipengaruhi oleh beberapa faktor, diantaranya adalah mangsa, tanaman (jenis, umur serta struktur tanaman), faktor fisik (cahaya, warna, bentuk), dan faktor kimia yang berupa bau yang merangsang predator untuk menemukan mangsa (Metcalf \& Luckmann, 1994). Menurut Tarumingkeng (1994), beberapa faktor yang berperan dalam menentukan laju pemangsaan oleh predator adalah preferensi terhadap mangsa, kepadatan mangsa, kualitas makanan dan adanya mangsa alternatif.

Imago $P$. fuscipes sering berada di atas permukaan tanah atau pada bagian-bagian tersulit pada tanaman dengan berjalan melalui dahan atau batang daun kemudian mencari mangsa pada daun atau tajuk-tajuk tanaman. Berhubungan dengan kegiatannya dalam mencari mangsa dan mobilitas yang sangat tinggi, serta ditunjang dengan bentuk tubuh yang cenderung pipih, $P$. fuscipes dapat bergerak dengan lincah pada tempat-tempat yang sempit, atau menyebar pada permukaan tanah yang luas dan mencari makanan pada tempat lain apabila pada tanaman utama tidak ditemukan mangsa. Pada penelitian ini, ruang gerak imago predator dipersempit (pada stoples), akibatnya imago lebih mudah untuk menemukan mangsa yang diberikan pada helaian daun. Namun demikian, tampaknya naluri untuk tetap menyisakan mangsa demi keturunannya masih tetap diperlihatkan mangsa walaupun jumlahnya sedikit.

Tabel 4. Jumlah nimfa B. tabaci yang dimangsa per imago P. fuscipes jantan periode sore dan pagi

\begin{tabular}{lcc}
\hline \multicolumn{1}{c}{ Jumlah mangsa } & $\begin{array}{c}\text { Rata-rata nimfa yang dimangsa } \\
\text { per } 12 \text { jam di siang hari }\end{array}$ & $\begin{array}{c}\text { Rata-rata nimfa yang dimangsa } \\
\text { per } 12 \text { jam di sore hari }\end{array}$ \\
\hline 10 nimfa $B$. tabaci & $9,17 \mathrm{a} \pm 0,18$ & $9,23 \mathrm{a} \pm 0,13$ \\
20 nimfa B. tabaci & $18,43 \mathrm{~b} \pm 0,26$ & $18,31 \mathrm{~b} \pm 0,46$ \\
40 nimfa B. tabaci & $37,14 \mathrm{c} \pm 0,43$ & $37,48 \mathrm{c} \pm 0,77$ \\
80 nimfa B. tabaci & $76,40 \mathrm{~d} \pm 1,85$ & $76,63 \mathrm{~d} \pm 1,23$ \\
160 nimfa B. tabaci & $101,11 \mathrm{e} \pm 2,17$ & $100,11 \mathrm{e} \pm 1,77$ \\
\hline
\end{tabular}

Keterangan: Nilai rata-rata yang diikuti oleh huruf yang berbeda pada setiap kolom menunjukkan perbedaan yang nyata menurut Uji Jarak Berganda Duncan pada taraf $5 \%$. 
Pada perlakuan 160 nimfa $B$. tabaci per satu imago $P$. fuscipes, rata-rata nimfa yang dimangsa paling optimal adalah 101,1 ekor pada pengamatan sore, dan 100,1 ekor pada pengamatan pagi.

$P$. fuscipes aktif mencari dan memakan nimfa B. tabaci pada siang dan malam hari, serta memiliki kemampuan memangsa yang relatif sama antara siang dan malam hari. Diduga dalam penelitian ini, cahaya tidak terlalu berpengaruh terhadap kemampuan $P$. fuscipes dalam mencari dan menangani nimfa $B$. tabaci sebagai makanan. Hasil penelitian ini berbeda dengan pengamatan yang dilakukan oleh Laba (2001) yang menyebutkan bahwa $P$. fuscipes aktif mencari wereng sebagai makanan pada malam hari.

Kemampuan musuh alami dapat diukur dari kemampuannya untuk menemukan mangsa pada saat kepadatan mangsa rendah dan mengkonsumsi banyak mangsa pada saat populasi mangsa tinggi memangsa dengan pola makan yang terus meningkat dari jam ke jam.

Pemahaman hasil analisis tanggap fungsional ini dapat digunakan untuk mengevaluasi potensi musuh alami secara umum, namun mengaitkannya dengan kondisi di lapangan perlu memperhatikan berbagai faktor yang tidak dijumpai saat percobaan di rumah kaca. Faktor di lapangan yang mempengaruhi tanggap fungsional adalah keberadaan predator lain, keadaan lingkungan dan kerapatan tanaman. Pada percobaan ini, baru terungkap satu faktor yang mempengaruhi tanggap fungsional, yaitu tahap perkembangan mangsa (imago). Faktor lain yang dapat mempengaruhi tanggap fungsional adalah fase pertumbuhan tanaman, cuaca, kehadiran mangsa alternatif, kompetisi dari predator lain dan tanaman inang (Metcalf \& Luckmann, 1994).

Tabel 5. Kecepatan memangsa $P$. fuscipes terhadap B. tabaci setelah 2 jam, 4 jam, 6 jam, dan 12 jam

\begin{tabular}{|c|c|c|c|c|c|c|c|c|c|c|}
\hline \multirow{3}{*}{ Jumlah mangsa } & \multicolumn{8}{|c|}{$\begin{array}{c}\text { Jumlah } B . \text { tabaci yang dimangsa (ekor) pada siang } \\
\text { dan malam setelah }\end{array}$} & \multicolumn{2}{|c|}{$\begin{array}{l}\text { Konsumsi mangsa } \\
\text { per jam (ekor) }\end{array}$} \\
\hline & \multicolumn{2}{|c|}{2 jam } & \multicolumn{2}{|c|}{4 jam } & \multicolumn{2}{|c|}{6 jam } & \multicolumn{2}{|c|}{12 jam } & \multirow[t]{2}{*}{ Siang } & \multirow[t]{2}{*}{ Malam } \\
\hline & $\mathrm{s}$ & $\mathrm{m}$ & $\mathrm{s}$ & $\mathrm{m}$ & $\mathrm{s}$ & $\mathrm{m}$ & $\mathrm{s}$ & $\mathrm{m}$ & & \\
\hline 10 nimfa $B$. tabaci & 3 & 2 & 5 & 5 & 7 & 7 & 10 & 9 & 0,83 & 0,75 \\
\hline 20 nimfa $B$. tabaci & 4 & 4 & 9 & 8 & 13 & 14 & 18 & 18 & 1,5 & 1,5 \\
\hline 40 nimfa $B$. tabaci & 7 & 6 & 13 & 14 & 21 & 20 & 36 & 34 & 3 & 2,83 \\
\hline 80 nimfa $B$. tabaci & 7 & 7 & 17 & 16 & 27 & 28 & 71 & 74 & 5,91 & 6,17 \\
\hline 160 nimfa $B$. tabaci & 8 & 9 & 19 & 17 & 31 & 29 & 98 & 96 & 8,17 & 8 \\
\hline
\end{tabular}

Keterangan: Pengamatan dilakukan pada hari pertama perlakuan; s: siang, m: malam

(Jervis \& Kidd, 1996). Rata-rata kecepatan memangsa $P$. fuscipes adalah 0,83-8,17 nimfa $B$. tabaci per jam. Penambahan nimfa $B$. tabaci menyebabkan meningkatnya jumlah nimfa yang dimangsa oleh $P$. fuscipes yang berkaitan dengan tanggap fungsional yang diberikan oleh predator terhadap ketersediaan mangsa (Tabel 5).

Imago $P$. fuscipes yang diberi mangsa 80 dan 160 ekor nimfa $B$ tabaci, memangsa nimfa $B$. tabaci paling banyak setelah 12 jam. Pada jumlah mangsa 10, 20, dan 40, P. fuscipes memangsa nimfa $B$. tabaci lebih banyak pada 6 jam pertama. Fakta ini semakin memperjelas adanya tanggap fungsional $P$. fuscipes terhadap $B$. tabaci sebagai mangsanya. Dengan mangsa yang berlimpah, predator cenderung

\section{SIMPULAN}

Siklus hidup Paederus. fuscipes berkisar antara 3875 hari dengan fase telur berkisar 4-7 hari, larva instar-1 berkisar 4-5 hari, larva instar-2 berkisar 6-9 hari, pra-pupa berkisar 2-3 hari, pupa berkisar 3-5 hari, dan imago berkisar 19-46 hari. Jumlah pemangsaan nimfa $B$. tabaci tertinggi terjadi pada kepadatan 160 nimfa, yaitu 101,1 dan 100,1 nimfa $B$. tabaci per imago $P$. fuscipes, masing-masing untuk periode pagi dan sore. Kecepatan memangsa imago $P$. fuscipes terhadap nimfa $B$. tabaci yaitu berkisar 0,83-8,17 nimfa per jam pada siang hari, dan 0,75-8 nimfa per jam pada malam hari. 


\section{DAFTAR PUSTAKA}

Clausen, CP. 1972. Entomophagous Insects. Reprinted Hafner Publishing Company. New York. 688 pp.

Devi, PK, DN Yadav and A Jha. 2004. Predatory behaviour and feeding potential of Paederus fuscipes. Gujarat Agricultural University. Anand. India. AGRIS record FAO. http://www.fao.org/agris/search/display.do. (Diakses 7 September 2008).

Feraru, E and G Mustata. 2004. The predators and the parasitoids insects in the colonies of Aphids (Homoptera: Aphididae) deleterious to the fruit trees from vaslui county. Al.I.Cuza. University of Iasi.

http://www.bio.uaic.ro/Anale/biol_an/2004/ Feraru_Elena.pdf. (Diakses 17 Juni 2008).

Hirano, K, E Budiyanto and S Winarni. 2006. Biological characteristics and forecasting outbreaks of the whitefly, Bemisia tabaci, a Vector of Viruses diseases in soybean fields. http://www.agnet.org/library/article/tb135. html. (Diakses 11 Oktober 2008).

Jha, A, PK Devi and DN Yadav. 2002. Biology of Paederus fuscipes Curtis (Coleoptera: Staphylinidae). CABI Abstracts.

http://www.cabi.org. (Diakses 9 November 2008).

Jervis, M and N Kidd. 1996. Insect Natural Enemies, Practical Approaches to Their Study and Evaluation. Chapman \& Hall. London. 491p.

Laba, IW. 2001. Keanekaragaman hayati artropoda dan peranan musuh alami hama utama padi pada ekosistem sawah. Makalah Falsafah Sains Program Pasca Sarjana IPB. http://tumoutou.net/3_sem1_012/i_w_laba. htm. (Diakses 9 November 2008).

Laba, IW and D Killin. 1994. Paederus fuscipes Curt. biology and feeding ability of brown planthoper (Nilaparvata lugens Stall). AGRIS Record FAO.

http://www.fao.org/agris/search/display.do;j sessionid=C8CF9B80CF9C12DFC66E2C5C6 97CA8FF?f=./1998/v2401/ID1997000441.xm 1;ID1997000441 (Diakses 9 November 2008).
Metcalf, R and WH Luckmann. 1994. Pest Management Concept. Pp 1-35 in Introduction to Insect Pest Management. Metcalf, R and WH Luckmann (Eds). John Wiley \& Sons, Inc., New York.

Petersen, MK. 1997. Life Histories of two Predaceous Beetles, Bembidion lampros and Tacchyporus hypnorum in the Agroecosytem. Acta Universitatis Sueciae Agraria. 35:1-37

Rahardjo, BT, S Karindah dan N Sujatmika. 1997. Biologi dan daya mangsa Paederus fuscipes (Coleoptera: Staphylinidae) Curtis terhadap Plutella xylostella (Lepidoptera: Plutellidae) Linnaeus di laboratorium. Habitat. 9:13 22.

Setiawati, W, BK Udiarto dan A Muharam. 2005. Pengenalan dan Pengendalian Hama-hama Penting pada Tanaman Cabai Merah. Panduan Teknis PTT Cabai Merah. No. 3. Balitsa, Lembang.

Sosromarsono, S. dan K. Untung. 2006. Keanekaragaman hayati artropoda predator dan parasit di Indonesia dan pemanfaatannya. http://kasumbogo.staff.ugm.ac.id/ detailarticle (Diakses 9 Oktober 2008).

Sudarjat, 2008. Potensi Berbagai Musuh Alami Asal sentra Produksi Tanaman Sayuran di Jawa Barat untuk Mengendalikan Kutu Kebul (Bemisia tabaci Genn.). Disertasi. Program Pascasarjana Universitas Padjadjaran Bandung.

Tarumingkeng, R C 1994. Dinamika Populasi, Kajian Ekologi Kuantitatif. Pustaka Sinar Harapan. 284 hal.

Taulu, L A. 2001. Kompleks Artropoda Predator Penghuni Tajuk Kedelai dan Peranannya dengan Perhatian Utama pada Paederus fuscipes (Curt.) (Coleoptera: Staphylinidae). Disertasi. Program Pascasarjana Institut Pertanian Bogor.

Untung, K. 1996. Pengantar Pengelolaan Hama Terpadu. Gadjah Mada University Press. Yogyakarta. 273 hal. 